\title{
A New Cognitive Framework for Understanding Social Commerce: A Service Ecosystem Perspective
}

\author{
Yingliang $\mathrm{Wu}^{1,2}, \mathrm{Xu} \mathrm{Chen}^{1^{*}}$ \\ ${ }^{1}$ Department of E-Business, School of Economics and Commerce, South China University of Technology, Guangzhou, China \\ ${ }^{2}$ Research Centre of Business Intelligence, Institute of Modern Service Industry, South China University of Technology, \\ Guangzhou, China \\ Email: *1977826530@qq.com
}

How to cite this paper: Wu, Y. L., \& Chen, X. (2020). A New Cognitive Framework for Understanding Social Commerce: A Service Ecosystem Perspective. Journal of Service Science and Management, 13, 459-469. https://doi.org/10.4236/jssm.2020.133031

Received: April 6, 2020

Accepted: May 19, 2020

Published: May 22, 2020

Copyright (๑) 2020 by author(s) and Scientific Research Publishing Inc. This work is licensed under the Creative Commons Attribution International License (CC BY 4.0).

http://creativecommons.org/licenses/by/4.0/

\begin{abstract}
Under the background of social network, Social Commerce has become one of the most popular front issues in business transformation and digital commerce. Based on the idea of Service Science and ecosystem, this paper abstracts social business network into a service system, and proposes a new cognitive framework of Social Commerce Ecosystem Model. From the five aspects of common support, social network service platform, service ontology and resource, service operating and collaborating, and service application, an open, dynamic and collaborative ecosystem is constructed to lay an important foundation for further research and disclosure of the ecological structure and business model of Social Commerce industry.
\end{abstract}

\section{Keywords}

Social Networks, Social Commerce, Service Ecosystem, Cognitive Framework

\section{Introduction}

In the new round of digital transformation, the social characteristics of the evolution and change of network service and e-commerce ecosystem are increasingly strengthened, and the impact on economic and social development is increasingly prominent. First of all, the new generation of Internet is becoming a key digital platform and hub for design, production, trade, information and the interaction and integration of various new technologies, which plays an important role in the construction of a digital general technology and infrastructure system for economic and social development (UNCTAD, 2017). Secondly, cloud 
computing, the Internet of things, mobile Internet, social network, electronic payment, social media and big data, a new generation of artificial intelligence (AI), advanced robots, maker movement are developing rapidly. Their integration and interaction are leading to industrial evolution and major changes in business models. The development process of business transformation and e-commerce ecology has entered a new round of digital transformation and development stage of industrial integration, big data, socialization and intelligent evolution and innovation (Meeker, 2019; Ministry of Commerce, 2019). Third, the rise and wide penetration of social networks further intensifies the networking and digital transformation of social development, and makes digital governance face multiple challenges (Chen, 2017; Jiang, 2019).

In this context, "Social Commerce" has become one of the most popular cutting-edge issues of business transformation and digital commerce, and is regarded as one of the new business model changes driving and leading the future business and economic prosperity. At the same time, in the current turn of interdisciplinary research paradigm, business science and management begin to adopt the biological "Ecosystem" thought (Vargo \& Lusch, 2004), and its research and exploration show the evolution of "Ecosystem $\rightarrow$ Organizational Ecosystem $\rightarrow$ Business Ecosystem", while the introduction of service dominant logic and the development of Service Science give birth to a new concept- "Service Ecosystem" provides a new perspective for us to newly recognize and depict the evolution of social business model.

In view of this, on the basis of reviewing the existing literature, this paper aims to examine and recognize the Social Commerce more systematically from the new perspective of "Service Ecosystem", and propose a new research framework of the business model of Social Commerce based on the concept of "Service Ecosystem". Based on the theories of Service Science and ecosystem, and the system architecture models and methods such as cloud service, social network service (SNS) and business analysis (BA), the analysis and design of Social Commerce service ecosystem are carried out. This paper adopts the system mechanism of dynamic, open, distributed interaction, loose coupling integration and coordination to construct the operation model of Social Commerce, points out the significance and value of the design and innovation of business model of Social Commerce based on the Service Ecosystem, and finally gives the research conclusion and enlightenment.

\section{Related Work}

\subsection{Social Commerce Research Perspective}

Thanks to the rapid development and wide application of cloud computing, Internet of things (IOT), mobile Internet, online social network and artificial intelligence platforms and tools, people's understanding of Social Commerce has gradually improved and deepened. "Social commerce" (SC) is the abbreviation of "Social E-commerce". As a new interdisciplinary field to be systematically 
studied and expanded (Hu, 2012; Tao et al., 2015; Zhang et al., 2016), although there has been a relatively active academic research in recent years (Lin et al., 2017; Hsu, 2019), the perspective and research topic are gradually expanded and scattered, and lag behind the rapid development of practice (Sukrat et al., 2018; Wu et al., 2018; Cheng et al., 2019).

At present, academia mainly studies and explains the Social Commerce from the perspectives of User Generated Content (UGC) (Liang, 2011), word-of-mouth communication ( $\mathrm{Li}$ et al., 2017), communication and interaction (Wang \& Zhang, 2012), business model (Nutley, 2010), value chain (Yadav et al., 2013; Wu et al., 2014) and other different disciplines (Marsden, 2010; Stephen et al., 2010). But there are few researches on the cognition and characterization of Social Commerce from the perspective of Service Ecosystem.

We mainly understand and define Social Commerce from the perspective of business model: it refers to e-commerce activities based on social network platform or tools (including community, blog, Microblog, Wechat and other social media software or tools), which is a new type of e-commerce model that reflects social value in the context of network socialization and social media situation. It should be noted that the operation model of Social Commerce runs through the whole Service Ecosystem. The Service Ecosystem of Social Commerce includes offline businesses, e-commerce platforms, logistics enterprises, payment platforms and social networks. However, the interaction between the subjects of business activities presents multi-dimensional interaction, that is, it includes communication between social customers and social enterprises, between social customers, between social customers and social platforms, between social enterprises and social platforms, and between online and offline enterprises.

There are usually two forms of Social Commerce (Liang, 2011). First, "e-commerce platform + social" mode, that is, adding social content to traditional e-commerce platform or promoting commodities by relying on social functions, such as Pinduoduo and other group buying websites. Second, "social platform + business" mode, that is, adding business functions to social platforms (social networking sites or social media sites) to guide people to consume in social places, such as Xiaohongshu, Wechat mall, etc.

\subsection{Service Ecosystem}

Vargo and Lusch $(2004,2008)$ proposed “Service Dominant Logic" (SDL), emphasizing that service is the foundation of all economies. From the perspective of service centered, Service Dominant Logic emphasizes four basic principles: value co creation, service exchange, resource integration and situational value. Its essence is that customers and enterprises interact through resource integration in service exchange and create value in specific situations (Lusch et al., 2014).

The ecosystem perspective provides a comprehensive social and institutional framework to describe the relationship between business and non-business, so it is more and more relevant in the application and expansion of Service Dominant 
Logic (Vargo, 2014). Vargo and Lusch $(2010,2011)$ put forward the concept of service ecosystem based on the thought of Service Dominant Logic and ecosystem, which is defined as "a relatively independent and self-regulating system formed by resource integrators through the connection of sharing system arrangement and mutual value creation based on service exchange" (Vargo \& Lusch, 2010, 2011). Letaifa and Reynoso (2015) pointed out that the combination of Service Dominant Logic and ecosystem characteristics creates a new service ecosystem framework. The core idea of Service Ecosystem is that participants interact with each other through resource integration and institutional constraints in the service exchange of dynamic and multi-level Service Ecosystem structure and create value together in specific situations (Lusch et al., 2014).

\section{Social Commerce Framework Based on Service Ecosystem}

Under the new social network technology and service environment, in order to better observe and understand the generation and evolution of Social Commerce service network, and then systematically and deeply study and describe the system structure, operation mechanism and service mode of Social Commerce, it is necessary to break through the limitations of the previous system view in comprehensively understanding and describing the structure and characteristics of Social Commerce system. Therefore, we propose a new architecture model of Social Commerce-Social Commerce Ecosystem Model (SCEM).

\subsection{Overview of Social Commerce Ecosystem Model}

The Social Commerce Ecosystem Model we proposed is shown in Figure 1.

It consists of five layers: Public Support Layer, Social Network Service Platform Layer, Domain Service Ontology and Resource Layer, Service Operating and Collaborating Layer, and Service Application Layer.

1) Common Support Layer

The Common Support Layer is the infrastructure layer of Social Commerce, which can be described as "social network computing infrastructure platform" abstractly. It is not only the technical foundation and platform of the whole Social Commerce service architecture, but also the social network computing and service environment of the system operation. First of all, this foundation and platform are built on a series of Internet technology and service basic standards, such as Resource Description Framework (RDF) (RDF Working Group, 2014), Web Service Resource Framework (WSRF) (Barry, 2020), cloud computing and cloud service standards, etc.; Secondly, this foundation and platform is a dynamic, open and diversified common support platform for social network services, including cloud service platforms from different service providers and service community networks for different basic businesses, such as social media tools and platforms, social network platforms, virtual communities, etc.

The Common Support Layer is the common technology support platform of 


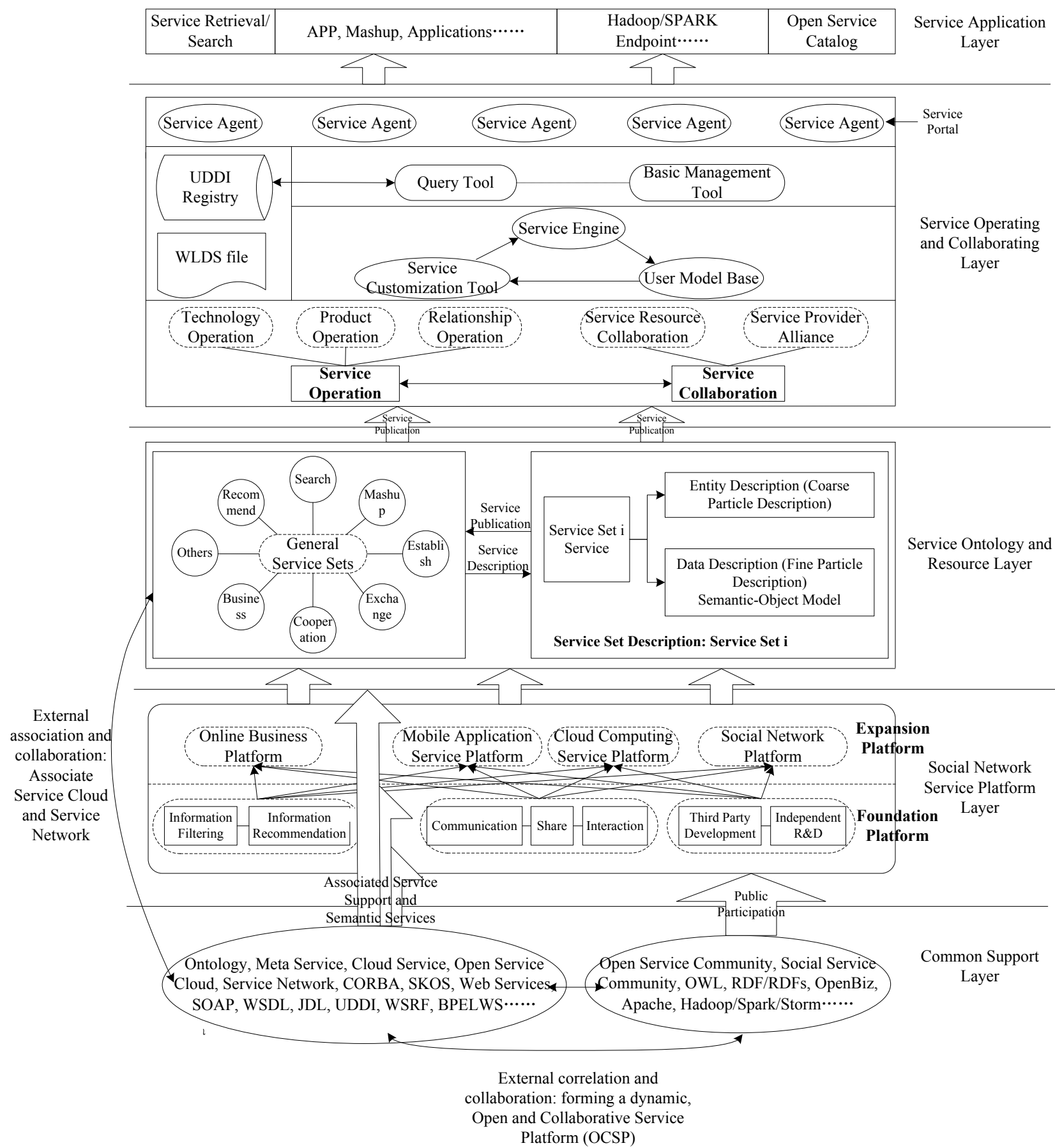

Figure 1. An architecture of the proposed social commerce ecosystem.

the Social Commerce system. Its prominent feature is more open and convenient than the traditional e-commerce operation system, which is mainly manifested in socialization, mobility and localization (Laudon et al., 2016). Through this Common Support Layer, enterprises can provide diversified network services, and the public can also communicate, interact and collaborate.

2) Social Network Service Platform Layer

Running on the Common Support Layer is the Social Network Service Plat- 
form Layer, which is composed of service foundation platform and service expansion platform. Services of this layer belong to general network services, such as general information search, recommendation and other network services. Based on the service expansion of the foundation platform, a variety of professional service platforms have been formed, including online business platform, mobile application service platform, cloud computing service platform and social network platform.

3) Service Ontology and Resource Layer

In the Service Ontology and Resource Layer, information resources and tools of existing social network services (SNS) are made full use of to realize the construction of service set in the open social network environment, including description and release. The construction and description of the general service set based on the meta-service corresponding to the Social Commerce Construct (SCC) (Hajli et al., 2017) is the core working mechanism of this layer, corresponding to the specific business logic of Social Commerce. Among them, the meta-services in the general service sets include search, recommendation, comment, exchange and other basic services.

4) Service Operating and Collaborating Layer

The Service Operating and Collaborating Layer provides the operation, collaboration mechanism of Social Commerce services, and realizes the integration and collaboration of business logic and business process. Service operation includes the operation of products, services and relationships, and service collaboration includes service resource collaboration and service provider alliance to achieve seamless connection and collaboration among services from different sources; Based on service formal definition and description methods such as Web Service Description Language (WSDL), service discovery and customization mechanism are provided for users through user model, service engine and service customization tools; On this basis, service agents for different applications are constructed to form the service portal of Social Commerce system, then users can access or acquire services seamlessly.

5) Service Application Layer

The Service Application Layer represents a variety of Social Commerce applications, corresponding to a variety of increasingly rich application scenarios. In this layer, value creation and sharing including Social Analysis (SA) and Social Intelligence (SI) are realized. Among them, service portal is the interface that organically connects services and users, namely "Service Encounter".

\subsection{New or Improved to Extant Research Framework on S-Commerce}

Based on the cloud service, service science and ecosystem thought, the research and proposal of this model abstracts Social Commerce network into a service system, which is of great significance and value to further understand and recognize the mechanism and characteristics of Social Commerce Service Ecosystem. It is shown in the following aspects: 
1) Developing and deepening of existing models

The framework model of Social Commerce Ecosystem proposed in this paper is to understand and depict the system structure, operation mechanism and service mode of Social Commerce Ecosystem with the integrated system view and methodology of service ecosystem. It is the expansion and deepening of existing Social Commerce models, such as understanding model (Wang \& Zhang, 2012) and contingency framework model (Yadav et al., 2013), with more comprehensive and systematic understanding and description ability.

2) Strengthening the expression ability of network service mechanism and characteristics in the Social Commerce environment

In the social computing network service mode, compared with the traditional e-commerce service, the Social Commerce service has more prominent characteristics such as openness, socialization, collaboration and data-driven, which are embodied in interaction, fragmentation, decentralization and user driven. The framework proposed in this paper takes service as the main line, customer as the center, runs through the process of Social Commerce services. The five-layer architecture of dynamic, open, distributed, loose coupling integration and collaboration strengthens the representation of the mechanisms and characteristics on Social Commerce services.

3) Providing a more open, inclusive and sustainable research framework for innovative development

With the in-depth and practical development of Social Commerce research, its connotation, extension and application mode will evolve dynamically (Lin et al., 2017; Hsu, 2019). Its research perspective, theme and direction will be continuously enriched and expanded under the influence of technological and business changes (Baethge et al., 2016; Tian et al., 2017; Shao, 2019). The hierarchical open structure of this framework model and the loosely coupling integration and coordination mechanism make each level of the model relatively independent. At the same time, it becomes a whole through internal and external correlation. With the ability of horizontal correlation and vertical integration, it also has strong dynamic absorption and adaptive development ability for new technologies and new services. It can absorb or add corresponding technologies or service components as needed. Therefore, just like the classic operation framework model of e-commerce (Turban et al., 2015), it provides a systematic framework of sustainable innovation development for the research and practice of Social Commerce.

In previous studies on the operation framework of Social Commerce, Liang (2011) proposed the research framework of Social Commerce including six key elements: research themes, social media, business activities, basic theories, achievements and research methods. Zhou et al. (2013) integrated the understanding of Social Commerce framework from four key components: business, technology, personnel and information. Hanz et al. (2017) focused on the psychological characteristics of consumers and constructed a framework system of consumers, business platforms and situations. In order to better understand the 
generation and evolution of Social Commerce service network, the operation framework put forward in this paper is more from the perspective of service ecosystem with a holistic view of the Social Commerce ecosystem.

\section{Contributions and Implications}

The rise and rapid development of Social Commerce is further influencing and even changing today's economic development and social development landscape, which provides a new paradigm for the change and innovation of business model.

In recent years, driven by multiple changes of technological innovation, user demand and industrial upgrading, the development of e-commerce has entered a new stage of big data, socialization and intelligence characterized by data-driven, open collaborative innovation, business model reconstruction and industrial integration. Social Commerce will become an important field of business model innovation and new business form formation in the mode evolution and ecological prosperity of e-commerce. China has a huge scale of Internet information infrastructure, user scale, e-commerce market and other Internet assets, and Social Commerce has great development potential. On this basis, it is of great significance to build a dynamic, open, distributed and collaborative social innovation paradigm, activate and develop the innovation consciousness and potential of the vast social groups, and promote the new digital transformation strategy and implementation of enterprises.

Based on the investigation of the evolution and innovation trend of the Social Commerce ecosystem under the background of social computing and big data, this paper puts forward the important issues of the service innovation and value collaborative creation of the Social Commerce Service Ecosystem. Based on the perspective of service science and system integration, this paper also proposes a comprehensive research framework, discusses the framework of Social Commerce Ecosystem under the background of Internet and digitalization. From the five aspects of Common Support Layer, Social Network Service Platform Layer, Service Ontology and Resource Layer, Service Operating and Collaborating Layer, and Service Application Layer, we build a dynamic collaborative ecosystem, which lays an important foundation for further research on the ecological structure and business model of Social Commerce system.

The academic contributions and implications of this study are as follows:

1) Innovation of Research Perspective

Based on the perspective of service ecosystem, this paper studies and depicts the operation mode of Social Commerce, pays attention to the mechanism of collaborative value creation and sharing. The dynamic evolution perspective is conducive to overcoming the limitations of static research.

2) Innovation of Research Framework

Under the guidance of Social Commerce ecology and socialized open collaborative innovation under the background of big data, network computing and 
service socialization, an open, integrated and collaborative structure and operation framework model of Social Commerce Service Ecosystem is innovatively put forward. The research system of Social Commerce has been expanded and deepened, which is conducive to enriching and improving the theory of Social Commerce and building a Social Commerce ecosystem with an overall view, complete system and coordinated operation.

3) Further Expanding the Research Theme of Social Commerce

A systematic review of the literature shows that the research themes of social commerce are mainly focused on advertising, word-of-mouth and organization (Lin et al., 2017). More detailed research themes are divided into 9 aspects such as user behavior, business model, website design, adoption strategy, research framework, social processes, network analysis, security and privacy strategy, and enterprise performance, of which user behavior accounts for the largest proportion (Husalim et al., 2016). However, it is rare to pay attention to the research of enterprise decision-making and the whole industry ecosystem (Bian et al., 2019). While expanding the research theme of Social Commerce, this paper also provides guidance for future research, such as the design and innovation of services in the Social Commerce Ecosystem, the benefit distribution of stakeholders, and the user-oriented creation of social intelligent applications. In addition, it provides systematic guidance and helps for Social Commerce practices such as system analysis and design of Social Commerce systems (Sukrat et al., 2018).

\section{Conflicts of Interest}

The authors declare no conflicts of interest regarding the publication of this paper.

\section{References}

Baethge, C., Klier, J., \& Klier, M. (2016). Social Commerce: State-Of-The-Art and Future Research Directions. Electronic Markets, 26, 269-290. https://doi.org/10.1007/s12525-016-0225-2

Barry, D. K. (2020). Web Services Resource Framework (WSRF). https://www.service-architecture.com/articles/web-services/web_services_resource_fra mework_wsrf.html

Bian, Y. W., Yan, X., \& Yang, L. X. (2019). Operations Management Decision Issues from the Social Learning Perspective. Journal of Management Sciences in China, 22, 18-27.

Chen, L. D. (2017). Internet Reconstructs Our Social Life. Xinhua News Digest, 9, 145-147.

Cheng, X., Gu, Y., \& Shen, J. (2019). An Integrated View of Particularized Trust in Social Commerce: An Empirical. International Journal of Information Management, 45, 1-12. https://doi.org/10.1016/j.ijinfomgt.2018.10.014

Hajli, N., Sims, J., Zadeh, A. H. et al. (2017). How Social Commerce Constructs Influence Customers' Social Shopping. Technological Forecasting \& Social Change, 2017, 1-13.

Hanz, H., \& Trimi, S. (2017). Social Commerce Design: A Framework and Application. Journal of Theoretical \& Applied Electronic Commerce Research, 12, 50-68. https://doi.org/10.4067/S0718-18762017000300005 
Hsu, L. C. (2019). Building Brand-Fan Relationships in Social Commerce Contexts: Mediators of Online Brand Relationships. Journal of Theoretical and Applied Electronic Commerce Research, 14, 106-123. https://doi.org/10.4067/S0718-18762019000200109

Hu, J. M. (2012). Study on Open Operation Architecture and Service Expansion of social Network Service. Information Science, 30, 1396-1400.

Husalim, A. H., \& Hussin, A. R. C. (2016). Understanding Social Commerce: A Systematic Literature Review and Directions for Further Research. International Journal of Information Management, 36, 1075-1088. https://doi.org/10.1016/j.ijinfomgt.2016.06.005

Jiang, Q. P. (2019). Six Reviews of Internet in 2018 and Seven Prospects in 2019. Internet Weekly, 1, 29-35.

Laudon, K. C., \& Traver, C. G. (2016). Electronic Commerce 2016: Business. Technology. Society (12th Edition). Boston: Pearson Education Inc., 26-36.

Letaifa, S. B., \& Reynoso, J. (2015). Toward a Service Ecosystem Perspective at the Base of the Pyramid. Journal of Service Management, 26, 684-705.

https://doi.org/10.1108/JOSM-04-2015-0133

Li, C. Y., \& Ku, Y. C. (2017). The Power of a Thumbs-Up: Will E-Commerce Switch to Social Commerce? Information \& Management, 2017, 1-18.

Liang, T. P., Ho, Y. T., Li, Y. W., \& Turban, E. (2011). What Drives Social Commerce: The Role of Social Support and Relationship Quality. International Journal of Electronic Commerce, 16, 69-90. https://doi.org/10.2753/JEC1086-4415160204

Liang, T. P., \& Turban, E. (2011). Introduction to the Special Issue Social Commerce: A Research Framework for Social Commerce. International Journal of Electronic Commerce, 16, 5-14. https://doi.org/10.2753/JEC1086-4415160201

Lin, X., Li, Y., \& Wang, X. (2017). Social Commerce Research: Definition, Research Themes and the Trends. International Journal of Information Management, 37, 190-201. https://doi.org/10.1016/j.ijinfomgt.2016.06.006

Lusch, R. F., \& Vargo, S. L. (2014). Service-Dominant Logic: Premises, Perspectives, Possibilities. New York: Cambridge University Press. https://doi.org/10.1017/CBO9781139043120

Marsden, P. (2010). Social Commerce: Monetizing Social Media. Munich: Grin Publishing.

Meeker, M. (2019). Internet Trends Report 2019. https://www.bondcap.com/pdf/190611_Internet_Trends_2019

Ministry of Commerce of the People's Republic of China (2019). 2018 China E-Commerce Development Report. https://dzswgf.mofcom.gov.cn/news_attachments/-20191111025029783.pdf

Nutley, M. (2010). Forget E-Commerce: S-Commerce Is Where It's at. Marketing Week, 2010-07-29.

RDF Working Group (2014). Resource Description Framework (RDF). http://www.w3.org/standards/techs/rdf

Shao, Z., \& Pan, Z. Y. (2019). Building Guanxi network in the mobile social platform: a social capital perspective. International Journal of Information Management, 44, 109-120. https://doi.org/10.1016/j.ijinfomgt.2018.10.002

Stephen, A. T., \& Toubia, O. (2010). Deriving Value from Social Commerce Networks. Journal of Marketing Research, 47, 215-228. https://doi.org/10.1509/jmkr.47.2.215

Sukrat, S., \& Papasratorn, B. (2018). An Architectural Framework for Developing a Recommendation System to Enhance Vendors' Capability in C2C Social Commerce. Social 
Network Analysis and Mining, 8, 1-13. https://doi.org/10.1007/s13278-018-0500-7

Tao, X. B., Yang, X. C., \& Xu, Y. (2015). Social Commerce Research: Review and Future Direction. Management Review, 27, 75-85.

Tian, X. M., \& Liu, L. B. (2017). Does Big Data Mean Big Knowledge? Integration of Big Data Analysis and Conceptual Model for Social Commerce Research. Journal of Electronic Commerce Research, 18, 169-183.

Turban, E., Kim, D., Mckay, J. et al. (2015). Electronic Commerce: A Managerial Perspective (8th Edition). London: Springer, 11-27. https://doi.org/10.1007/978-3-319-10091-3

UNCTAD (2017). Information Economy Report 2017. https://unctad.org/en/pages/PublicationWebflyer.aspx

Vargo, S. L., \& Lusch, R .F. (2011). It's All B2B and Beyond: Toward a Systems Perspective of the Market. Industrial Marketing Management, 40, 181-187. https://doi.org/10.1016/j.indmarman.2010.06.026

Vargo, S. L., \& Lusch, R. F. (2004). Evolving to a New Dominant Logic for Marketing. Journal of Marketing, 68, 1-17. https://doi.org/10.1509/jmkg.68.1.1.24036

Vargo, S. L., \& Lusch, R. F. (2008). Service-Dominant Logic: Continuing the Evolution. Journal of the Academy of marketing Science, 36, 1-10. https://doi.org/10.1007/s11747-007-0069-6

Vargo, S. L., \& Lusch, R. F. (2010). From Repeat Patronage to Value Co-Creation in Service Ecosystems: A Transcending Conceptualization of Relationship. Journal of Business Market Management, 4, 169-179. https://doi.org/10.1007/s12087-010-0046-0

Vargo, S. L., \& Lusch, R. F. (2014). Inversions of Service-Dominant Logic. Marketing Theory, 14, 239-248. https://doi.org/10.1177/1470593114534339

Wang, C., \& Zhang, P. (2012). The Evolution of Social Commerce: The People, Management, Technology, and Information Dimensions. Communications of the Association for Information Systems, 31, 105-127.

Wu, J. H., Gao, S., \& Mo, Z. (2014). Research on the Model Innovation of Social Commerce. Information Science, 12, 48-52.

Wu, Y. L., \& Chen, J. (2018). Review and Prospect of Social Commerce Research Based on Statistical Analysis of SSCI Papers from 2006 to 2016. Scientific Journal of E-Business, 7, 1-14.

Yadav, M. S., D Valck, K., Hennig-Thurau, T. et al. (2013). Social-Commerce: A Contingency Framework for Assessing Marketing Potential. Journal of Interactive Marketing, 27, 311-323. https://doi.org/10.1016/j.intmar.2013.09.001

Zhang, K. Z. K., \& Benyoucef, M. (2016). Consumer Behavior in Social Commerce: A Literature Review. Decision Support Systems, 86, 95-108.

Zhou, L. N., Zhang, P., \& Zimmermann, H. D. (2013). Social Commerce Research: An Integrated View. Electronic Commerce Research and Applications, 12, 61-68. 